\title{
Evaluation of Acceptance, Safety, and Expulsion of Postplacental Intrauterine Contraceptive Devices
}

lysverya Gnanasekar

\section{ABSTRACT}

Aims and objectives:

- To determine the proportion of women accepting immediate PPIUCD insertion.

- To determine the rates of expulsion, pelvic infection, lost strings, and displacement following PPIUCD insertion among the acceptors by 6 weeks.

Materials and methods: The material used in this study was copper T 380A.The modified kelly's forceps was used for the post placental insertion of copper T into the uterine cavity under aseptic precautions.

Results: The acceptance rate of copper T in this study was 26.44 .

- The expulsion rate of copper T at the end of 6 weeks was $2.22 \%$

- There were no cases of pelvic infection or displacement of copper $\mathrm{T}$ in this study.

Conclusion: The acceptance rate of copper $T$ was poor which was mainly attributable to the lack of sufficient knowledge about copper $\mathrm{T}$ and the false beliefs regarding the impact the copper $T$ has on the health of the individual. However in those women who accepted for copper $T$ insertion were satisfied with the copper T as a temporary method of contraception.

Keywords: Copper T 380A, Intrauterine contraceptive device, Postplacental intrauterine contraceptive device.

How to cite this article: Gnanasekar I. Evaluation of Acceptance, Safety, and Expulsion of Postplacental Intrauterine Contraceptive Devices. J South Asian Feder Obst Gynae 2018;10(2):118-122.

Source of support: Nil

Conflict of interest: None

Date of received: 15 March 2018

Date of acceptance: 20 April 2018

Date of publication: July 2018

\section{INTRODUCTION}

India has a population of 1.21 billion as per March 2011 census. ${ }^{1}$ Currently in India, $65 \%$ of the women in the first year postpartum have an unmet need for family planning. ${ }^{2}$ Therefore, this critical period needs to be focused

\section{Postgraduate Student}

Department of Obstetrics and Gynecology, Sri Ramachandra Medical College, Chennai, Tamil Nadu, India

Corresponding Author: lysverya Gnanasekar, Postgraduate Student, Department of Obstetrics and Gynecology, Sri Ramachandra Medical College, Chennai, Tamil Nadu, India e-mail: iysveryagt@gmail.com upon the most. Hence, the Ministry of Health and Family welfare, Government of India, introduced PPIUCD service in 19 states of India in 2010, in collaboration with Johns Hopkins Program for International Education in Gynecology and Obstetrics (JHPIEGO), India. ${ }^{3}$

Women and their family are easily motivated and very receptive to family planning advice during the postpartum period. Hence, this would be the best time when IUCD can be inserted with certainty that the female is not pregnant. This also saves an additional visit for the women staying in rural areas to the hospital where transport facilities are very limited.

The IUCD has been well known for its safety and efficacy since ages. It is a long-term method with minimal side effects, simple, reversible, high continuation rate, one-time motivation, and made freely available by the Government of India.

The IUCD is the most widely used method of contraception with approximately 160 million users worldwide. ${ }^{4-6}$ Globally, $14.3 \%$ of female contraceptive users prefer the IUCD. ${ }^{7}$ The effectiveness of copper IUCDs, especially CuT 380A, has been shown to be comparable to tubal sterilization over the long term, with the extra advantage of being easily reversible. ${ }^{8,9}$ The long-term discontinuation rates are generally low in spite of well-known complications, such as pain and increased menstrual bleeding. ${ }^{4,5,10}$

\section{AIMS AND OBJECTIVES}

- To determine the proportion of women accepting immediate PPIUCD insertion.

- To determine the rates of expulsion, pelvic infection, lost strings, and displacement following PPIUCD insertion among the acceptors by 6 weeks.

\section{Study Location}

Department of Obstetrics and Gynecology, Sri Ramachandra University, Porur, Chennai, Tamil Nadu, India

\section{Inclusion Criteria}

Consenting for copper $\mathrm{T}$ after counseling.

\section{Exclusion Criteria}

- Fever during labor and delivery

- Known to have ruptured membranes for more than 24 hours prior to delivery 


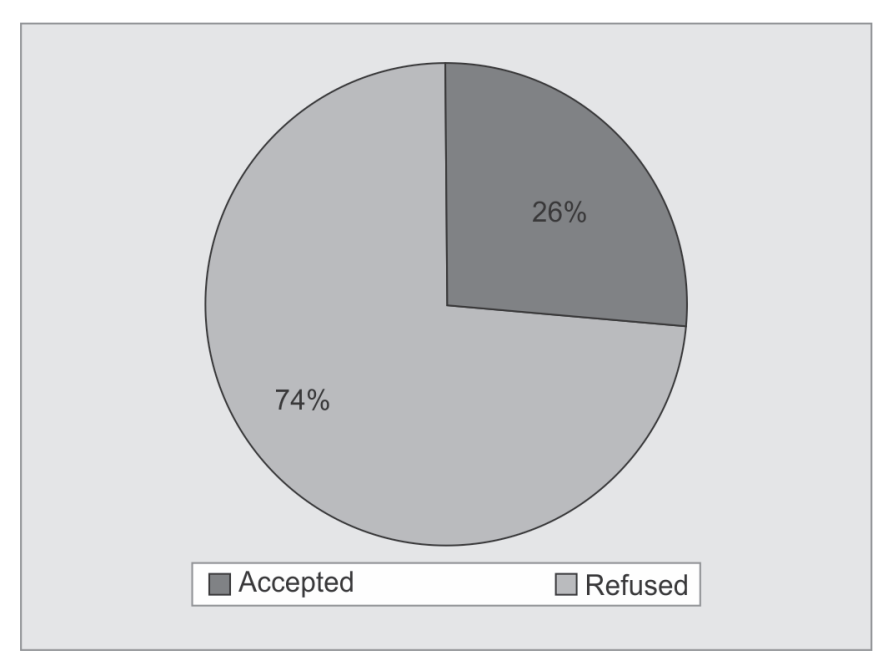

Graph 1: Acceptance rate

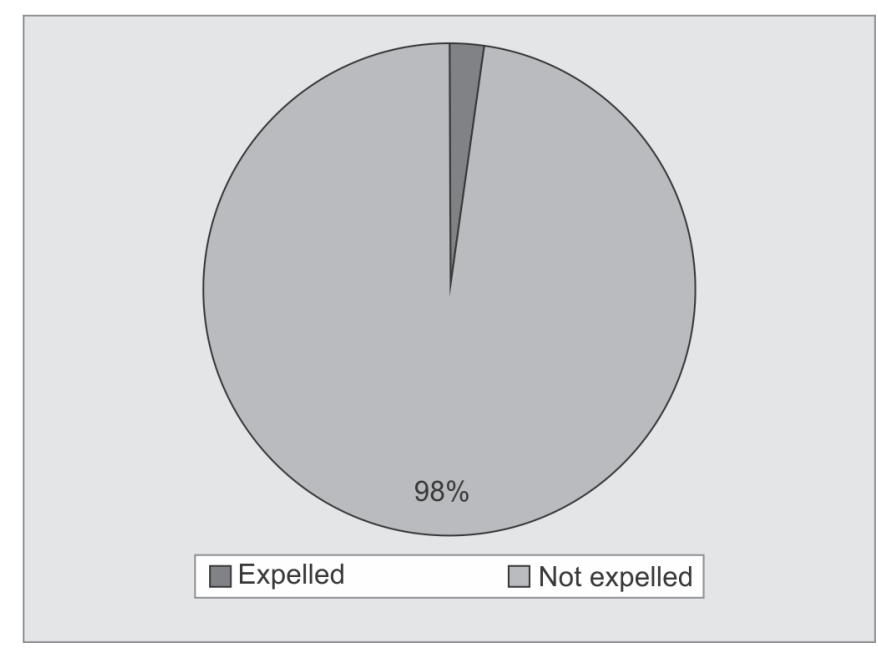

Graph 2: Expulsion rate
- Known uterine abnormalities

- Manual removal of placenta

- Postpartum hemorrhage

\section{MATERIALS AND METHODS}

\section{Materials}

The contraceptive device used in this study was copper T 380A.

\section{Methods}

\section{Postplacental Insertion}

- After performing appropriate handwashing, a pair of sterile gloves was worn.

- The perineum was cleaned with povidone iodine. The perineum, labia, and vaginal walls were inspected for lacerations.

- The cervix and vaginal walls were cleaned twice with gauze soaked in povidone iodine solution with speculum in place.

- The anterior lip of the cervix was then gently held with sponge-holding forceps.

- The IUCD was removed from the insertion sleeve and grasped with the modified Kelley forceps using no-touch technique.

- Once it is inserted into the lower uterine segment, the other hand was moved to the abdomen and placed over the fundus, and uterus was pushed gently upward to reduce the angle and curvature between the uterus and vagina.

- Intrauterine contraceptive device with forceps was moved upward until it can be felt at the fundus.

- Then the forceps was opened to release the IUCD and swept to side wall. Uterus was stabilized until forceps removal was complete.

- The cervical os was then gently inspected for the strings. Sims speculum was removed.

\section{Follow-up}

- All the patients who had copper T 380A inserted postplacentally were reviewed at 6 weeks to check for string status, any complaints, and to check for expulsions, pelvic infections, or displacements of copper $\mathrm{T}$.

- In patients who had strings not visible, ultrasound was done to confirm the position of the IUCD and to rule out displacement of the IUCD.

\section{RESULTS}

- The acceptance rate of copper $\mathrm{T}$ in this study was 26.44 (Graph 1).

- The expulsion rate of copper $\mathrm{T}$ at the end of 6 weeks was $2.22 \%$ (Graph 2).

- There were no cases of pelvic infection or displacement of copper $\mathrm{T}$ in this study.

\section{DISCUSSION}

Flow Chart 1 depicts the summary of the study.

As depicted in Table 1, in this study, we counseled 363 patients who delivered normally for postplacental copper $\mathrm{T}$ insertion out of which 96 women accepted for copper $\mathrm{T}$ insertion. The acceptance rate for copper $\mathrm{T}$ was $26.44 \%$, and majority of the women who accepted belonged to the graduate group of education of $40.62 \%$ as shown in Table 2, which explains the importance of education in the counseling process.

In a study by Garuda et $\mathrm{al}^{11}$ and Mishra, ${ }^{12}$ the maximum number of acceptors for copper $\mathrm{T}$ insertion belonged to the primipara group which accounted to 67.27 and $64.53 \%$, which is similar to this study in which primiparas accounted for $71.88 \%$ as shown in Table 3. However, in a study by Srivastava and Bano, ${ }^{13}$ the maximum number of acceptors belonged to the para 2 group which accounted for $36.86 \%$. 


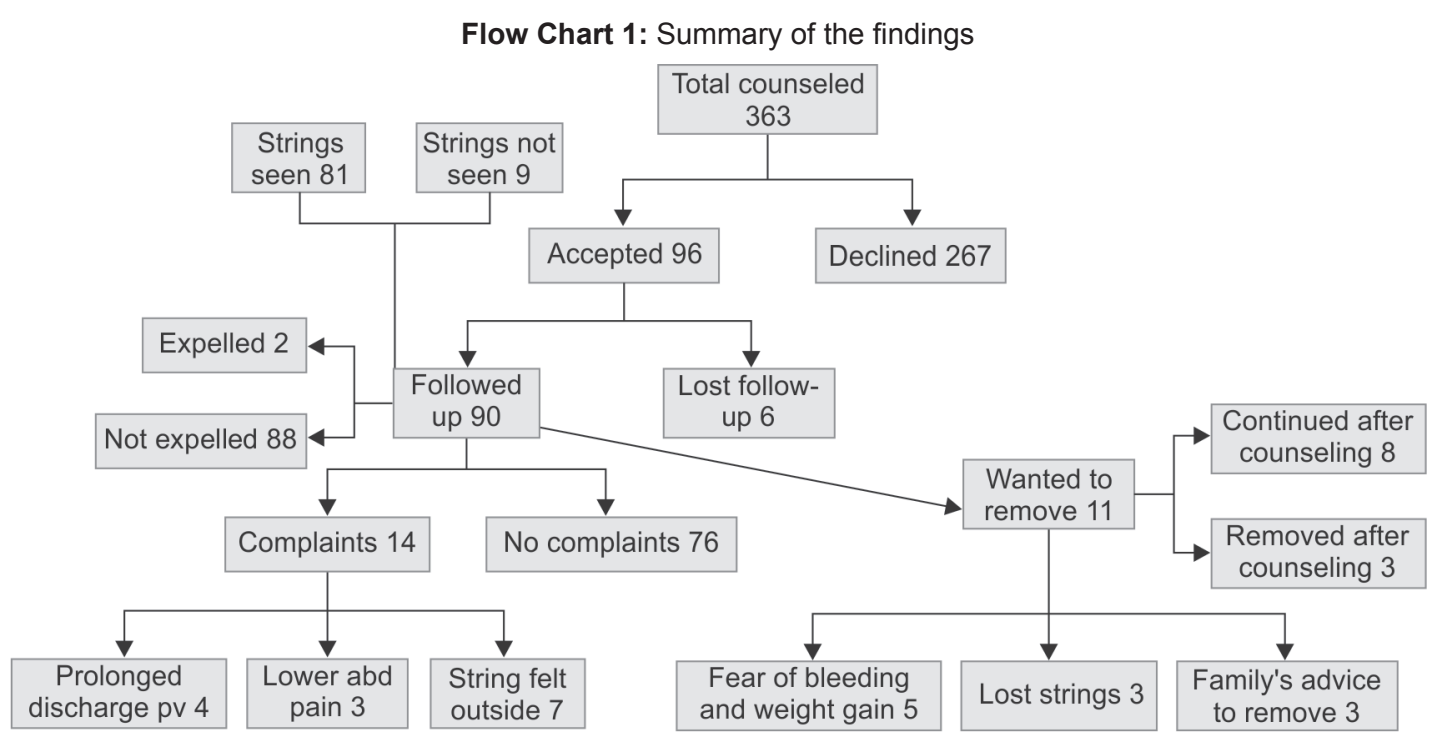

Table 1: Acceptance rate

\begin{tabular}{lll}
\hline Acceptance rate & Number & Percent \\
\hline Counseled & 363 & 100 \\
Accepted & 96 & 26.44 \\
Refused & 267 & 73.56 \\
\hline
\end{tabular}

Table 2: Education status of accepted women

\begin{tabular}{lll}
\hline Education status & $N=96$ & Percent \\
\hline Primary school & 0 & 0 \\
High school & 21 & 21.88 \\
Higher secondary & 36 & 37.5 \\
Graduate & 39 & 40.62 \\
Professional & 0 & 0 \\
\hline Total & 96 & 100 \\
\hline
\end{tabular}

Table 3: Paritywise classification of counseled women

\begin{tabular}{lll}
\hline Parity & Accepted & Percent \\
\hline Para 1 & 69 & 71.88 \\
Para 2 & 25 & 26.04 \\
Para 3 & 2 & 2.08 \\
\hline Total & 96 & 100 \\
\hline
\end{tabular}

Table 4: Reason for accepting copper $\mathrm{T}$

\begin{tabular}{lll}
\hline Reason & $N=96$ & Percent \\
\hline No interference with breastfeeding & 26 & 27.08 \\
Reversible & 25 & 26.05 \\
Few clinical visits & 5 & 5.22 \\
Long term & 12 & 12.5 \\
Doctor's advice & 11 & 11.45 \\
One-time procedure & 15 & 15.62 \\
Safe & 2 & 2.08 \\
\hline Total & 96 & 100 \\
\hline
\end{tabular}

In this study, the reason for majority of the women accepting copper $\mathrm{T}$ was because it has no interference with breastfeeding as shown in Table 4 . When the reasons for accepting copper $\mathrm{T}$ insertion was studied in
Table 5: Reason for refusing copper $T$

\begin{tabular}{lll}
\hline Reason & $N=267$ & Percent \\
\hline Chose permanent method & 15 & 5.62 \\
Family refusal & 17 & 6.37 \\
Fear of bleeding & 56 & 20.98 \\
Fear of loss of weight & 23 & 8.62 \\
Had already tried and not satisfied & 5 & 1.88 \\
Need to discuss with partner & 33 & 12.35 \\
Did not conceive spontaneously before & 5 & 1.88 \\
No reason & 45 & 16.85 \\
Satisfied with male barrier method & 15 & 5.61 \\
Had already tried and had to remove by & 1 & 0.37 \\
hysteroscopy & & \\
Prefers to use other method & 52 & 19.47 \\
\hline Total & 267 & 100 \\
\hline
\end{tabular}

different studies, each study had highlighted a different and unique reason which was picked up by majority of patients. In a study done by Garuda et $\mathrm{al}^{11}{ }^{11} 83.63 \%$ of patients accepted copper $\mathrm{T}$ since it is a one-time procedure when compared with other methods of temporary contraception, such as injectables or oral contraceptive pills which will have to be taken everyday.

In a study done by Mishra, ${ }^{12}$ the reason for maximum patients to accept copper T was "my doctor's advice must be a good one" which helps us to understand the importance of developing a good rapport with our patients which helps them to trust their doctor's choice more over other factors.

In the study by Garuda et $\mathrm{al}^{11}$ the reason for maximum number of patients refusing copper $\mathrm{T}$ was because they had to discuss with their partner who is the final decision-maker in the family as in most families in India; however, in this study, $20.98 \%$ of the women refused copper $\mathrm{T}$ due to fear of bleeding as shown in Table 5. Hence, this helps us to understand the need for patient and husband counseling right from the antenatal period during their check-up sessions. This would help 
Evaluation of Acceptance, Safety, and Expulsion of PPIUCD

\begin{tabular}{lll}
\hline \multicolumn{3}{c}{ Table 6: Age group of accepted women } \\
\hline Age (years) & $N=96$ & Percent \\
\hline$<20$ & 9 & 9.37 \\
$21-25$ & 55 & 57.29 \\
$26-30$ & 25 & 26.05 \\
$>30$ & 7 & 7.29 \\
\hline Total & 96 & 100 \\
\hline
\end{tabular}

Table 8: String status at 6 weeks

\begin{tabular}{lll}
\hline String status & $N=90$ & Percent \\
\hline String seen & 81 & 90 \\
String not seen & 9 & 10 \\
Total & 90 & 100 \\
Patients lost to follow-up & 6 & \\
\hline
\end{tabular}

Table 10: Willingness to retain copper $T$ at 6 weeks

\begin{tabular}{lll}
\hline Review at 6 weeks & $N=90$ & Percent \\
\hline Wanted to retain & 79 & 87.78 \\
Wanted removal & 11 & 12.22 \\
\hline Total & 90 & 100 \\
\hline
\end{tabular}

the doctor to clear their doubts and break the myths of copper $\mathrm{T}$ in their minds and encourage them for copper $\mathrm{T}$ insertion explaining its various other benefits, such as one-time procedure, no interference with breastfeeding, long acting, and reversible.

In the study by Srivastava and Bano ${ }^{13}$ and in this present study, the main reason for refusal was fear of bleeding which can again be overcome by promoting more health education in the forms of meetings, advertisements which aim at breaking the myths related to copper T insertion. Similarly, in the study by Mishra, ${ }^{12}$ the main reason for refusal was not enough knowledge about copper $\mathrm{T}$ which implies the need for more educational interactive sessions to be conducted with patients to bring about more awareness about copper $\mathrm{T}$.

The majority age group of women who accepted for copper $\mathrm{T}$ belonged to the age group of 20 to 25 years$57.29 \%$ in this study as shown in Table 6, where most of them are primiparas and copper $\mathrm{T}$ is an ideal method to delay the next pregnancy. In a study by Garuda et $\mathrm{al}^{11}$ and Mishra, ${ }_{1}^{12}$ the majority of the women who accepted for copper $\mathrm{T}$ belonged to the age group of 20 to 29 years, which accounted for 65.45 and $68 \%$. In the other studies also, the continuation rates at the end of 6 weeks were high, such as $92 \%$ in study by Sultana et al $^{14}$ and $81.11 \%$ in the study by Mishra. ${ }^{12}$

The total follow-up at the end of 6 weeks was $93.75 \%$ among which, $89.59 \%$ came to the hospital for followup and $4.16 \%$ were followed up on phone and $6.25 \%$ of the women were lost to follow-up as shown in Table 7 and out of which only $90 \%$ of the women had visible copper $\mathrm{T}$ strings on per speculum examination as shown
Table 7: Follow-up rate at 6 weeks

\begin{tabular}{lll}
\hline Follow-up & $N=96$ & Percent \\
\hline Came for follow-up & 86 & 89.59 \\
Followed up on phone & 4 & 4.16 \\
Lost to follow-up & 6 & 6.25 \\
\hline Total & 96 & 100 \\
\hline
\end{tabular}

Table 9: Complaints at 6 weeks

\begin{tabular}{lll}
\hline Complaints & $N=14$ & Percent \\
\hline Prolonged discharge per vaginum & 4 & 4.44 \\
Lower abdominal pain & 3 & 3.33 \\
String felt outside & 7 & 7.78 \\
\hline Total & 14 & 15.55 \\
\hline
\end{tabular}

Table 11: Reasons for wanting to remove copper $T$

\begin{tabular}{lll}
\hline Reasons & $N=11$ & Percent \\
\hline Fear of bleeding and weight gain & 5 & 5.56 \\
Lost strings & 3 & 3.33 \\
Family's advice to remove & 3 & 3.33 \\
\hline Total & 11 & 12.22 \\
\hline
\end{tabular}

Table 12: Status after counseling

\begin{tabular}{lll}
\hline Status after counseling & Number & Percent \\
\hline Wanted to remove & 11 & 12.22 \\
Wanted to remove after counseling & 3 & 3.33 \\
Wanted to continue after counseling & 8 & 8.88 \\
\hline
\end{tabular}

in Table 8 , and the remaining $10 \%$ were reassured and ultrasound pelvis was done and the presence and position of the copper $\mathrm{T}$ were confirmed to be intrauterine and to rule out any displacement or perforation of the copper $\mathrm{T}$.

At the end of 6 weeks, when the women came for review, most of the women were satisfied with the copper T and had no complaints, while $15.55 \%$ of the women had complaints, such as prolonged discharge per vaginum $(4.44 \%)$, abdominal pain $(3.33 \%)$, and string felt outside $(7.78 \%)$, as shown in Table 9, while it is similar to a study done by Sultana et $\mathrm{al}^{14}$ in which $29.3 \%$ had complaints of heavy bleeding per vaginum and $10 \%$ of the women had abdominal pain.

At the end of 6 weeks, when the women came for review, $12.22 \%$ of the women wanted to remove their copper $\mathrm{T}$ as shown in Table 10 and the main reason for the above was fear of bleeding which was $5.56 \%$ as shown in Table 11. All these women were counseled regarding their problems and reassurance was given following which 8.88 and 3.33 of the $12.22 \%$ decided to retain their copper $\mathrm{T}$ as shown in Table 12, and still the reason for removal of copper $\mathrm{T}$ was fear of bleeding in $2.22 \%$ of the women as shown in Table 13, which is similar to a study done by Mishra $^{12}$ in which the reason of majority of the women discontinuing copper $\mathrm{T}$ was bleeding. 
Table 13: Reasons for removal of copper $T$

\begin{tabular}{lll}
\hline Reasons & $N=3$ & Percent \\
\hline Fear of bleeding and weight gain & 2 & 2.22 \\
Family's advice to remove & 1 & 1.11 \\
\hline Total & 3 & 3.33 \\
\hline
\end{tabular}

Table 15: Expulsion rate at 6 weeks

\begin{tabular}{lll}
\hline Expulsion rate & $N=90$ & Percent \\
\hline Expelled & 2 & 2.22 \\
Not expelled & 88 & 97.78 \\
\hline Total & 90 & 100 \\
\hline
\end{tabular}

At the end of 6 weeks, the patients were followed up and those who requested removal were advised and majority of them decided to continue copper $T$ which accounted for $90.62 \%$ in this present study as shown in Table 14 .

In a study by Afshan and Asim, ${ }^{15}$ the expulsion rate of copper $\mathrm{T}$ at 6 weeks was low, $6 \%$, and it was $4 \%$ in a study done by Halder et $\mathrm{al}^{16}{ }^{16}$ whereas in this study, the expulsion rate was $2.22 \%$ (Table 15 ).

\section{REFERENCES}

1. Gupta A, Verma A, Chauhan J. Evaluation of PPIUCD versus interval IUCD (380A) insertion in a teaching hospital of Western UP. Int J Reprod Contracept Obstet Gynecol 2013;2(2):204208.

2. Postpartum IUCD Reference Manual, Family Planning Division. Ministry of Health and Family Welfare, Government of India, New Delhi, India; 2010.

3. Asif R, Charunat E, Das S, Kumar S, Rath M, Saha S, Sethi R, Srivastava V, Yadav V. Revitalisation of PPIUCD services experience from India, Jhpiego/India (New Delhi). Contraception 2012 Aug;86(2):184-185.

4. Chi I. What we have learned from recent IUD studies: a researcher's perspective. Contraception 2003;68:3-10.

5. Fortney JA, Feldblum PJ, Raymond EG. Intrauterine devices. The optimal long-term contraceptive method? J Reprod Med 1999 Mar;44(3):269-274.
Table 14: Continuation rate

\begin{tabular}{lll}
\hline Continuation rate & $N=87$ & Percent \\
\hline Wanted to continue & 79 & 82.29 \\
Wanted to continue after counseling & 8 & 8.33 \\
\hline Total & 87 & 90.62 \\
\hline
\end{tabular}

6. d'Arcangues C. Worldwide use of intrauterine devices for contraception. Contraception 2007 Jun;75(6 Suppl):S2-S7.

7. Bühling KJ, Zite NB, Lotke P, Black K, INTRA Writing Group. Worldwide use of intrauterine contraception: a review. Contraception 2014;89(3):162-173.

8. Kulier R, O'Brien PA, Helmerhorst FM, Usher-Patel M, $\mathrm{D}^{\prime}$ Arcangues $\mathrm{C}$. Copper containing, framed intrauterine devices for contraception. Cochrane Database Syst Rev 2007 Oct 17;(4):CD005347.

9. United Nations Development Programme, United Nations Population Fund, World Health Organization, World Bank, Special Programme of Research, Development and Research Training in Human Reproduction. Long-term reversible contraception. Twelve years of experience with the TCu380A and TCu220C. Contraception 1997 Dec;56(6):341-352.

10. Andersson K, Ryde-Blomqvist E, Lindell K, Odlind V, Milson I. Perforations with intrauterine devices. Contraception 2014;89(3);162-173.

11. Garuda L, Kambham S, Neelohita B. Clinical outcome of PPIUCD (Copper-380A) - Intracesarean insertion. Indian J Obstet Gynaecol Res 2015;2(4):218-226.

12. Mishra S. Evaluation of safety, efficacy, and expulsion of post-placental and intra-cesarean insertion of intrauterine contraceptive devices (PPIUCD). J Obstet Gynecol India 2014Sep-Oct;64(5):337-343.

13. Srivastava S, Bano I. Acceptability of PPIUCD versus interval IUCD insertion. Int J Sci Res 2016 Aug;5(8):364-367.

14. Sultana R, Jameel A, Amjad A. Immediate postpartum insertion of intrauterine device: an ideal method. JSOGP 2015;5(1).

15. Afshan A, Asim S. Immediate postpartum IUCD (PPIUCD) insertion : an opportunity not to be missed. Ann Abbasi Shaheed Hosp Karachi Med Dent Coll 2014 Jun;19(1):15-20.

16. Halder A, Sowmya MS, Gayen A, Bhattacharya P, Mukherjee S, Datta S. A prospective study to evaluate vaginal insertion and intra-cesarean insertion of post-partum intrauterine device. J Obstet Gynecol India 2016 Jan-Feb;66(1):35-41. 